\title{
Periodontal disease and its impact on general health in Latin America. Section V: Treatment of periodontitis
}

\author{
Ricardo Guimarães FISCHER ${ }^{(a)}$ iD \\ Ronaldo LIRA JUNIOR(b) \\ Belén RETAMAL-VALDES(c) iD \\ Luciene Cristina de \\ FIGUEIREDO(c,d) iD \\ Zilson MALHEIROS(d,e) \\ Bernal STEWART ${ }^{(\mathrm{d}, \mathrm{e})}$ iD \\ Magda FERES(c,d) iD \\ (a) Universidade do Estado do Rio de Janeiro \\ - UERJ, Faculty of Dentistry, Department of \\ Periodontology, Rio de Janeiro, RJ, Brazil. \\ (b)Karolinska Institutet, Dental School, Department \\ of Periodontolgy, Stockholm, Sweden. \\ (c) Universidade de Guarulhos - UnG, \\ Dental Research Division, Department of \\ Periodontology, Guarulhos, SP, Brazil. \\ (d)Latin American Oral Health Association - \\ LAOHA, São Paulo, SP, Brazil. \\ (e) Colgate Palmolive Company, Global \\ Technology Center, Piscataway, NJ, USA.
}

Declaration of Interests: The authors certify that they have no commercial or associative interest that represents a conflict of interest in connection with the manuscript.

Corresponding Author: Ricardo Guimarães Fischer E-mail: ricfischer@globo.com

ht1ps://doi.org/10.1590/1807-3107bor-2020.vol34.0026

Submitted: September 8, 2019

Accepted for publication: September 22, 2019 Last revision: October 16, 2019

\begin{abstract}
Gingivitis and periodontitis are associated with a negative impact on Oral Health Related Quality of Life (OHRQoL), exerting a significant influence on aspects related to the patients' function and esthetics. Periodontitis has been associated with several systemic conditions, including adverse pregnancy outcomes, cardiovascular diseases, type 2 diabetes mellitus (DM), respiratory disorders, fatal pneumonia in hemodialysis patients, chronic renal disease and metabolic syndrome. The aim of this paper was to review the results of different periodontal treatments and their impacts on patients' OHRQoL and systemic health. Non-surgical and surgical periodontal treatments are predictable procedures in terms of controlling infection, reducing probing pocket depth and gaining clinical attachment. In addition, the treatment of periodontitis may significantly improve OHRQoL and promote a reduction in the levels of systemic markers of inflammation, including some cytokines associated with cardiovascular diseases. Studies have also suggested that periodontal treatment may improve glycemic control in patients with DM. Strategies and actions for preventing the onset and recurrence of periodontitis, and the challenges facing the field of periodontology in the XXI century are presented in this review.
\end{abstract}

Keywords: Periodontics; Periodontal Debridement; Quality of Life; Cardiovascular Diseases; Diabetes Mellitus.

\section{Introduction}

Periodontitis is a chronic multifactorial inflammatory disease associated with a dysbiotic biofilm and characterized by progressive destruction of the tooth-supporting apparatus, which can lead to tooth loss. ${ }^{1}$ Although it may progress with swelling and bleeding, periodontitis is normally considered a silent disease. However, this concept may not be accurate, since health and well-being are not merely medical concepts, but are encompassed by the biopsychosocial model. The American Dental Association (ADA) states that 'Oral health is a functional, structural, aesthetic, physiologic and psychological state of well-being and is essential to an individual's general health and quality of life'.2 Oral Health Related Quality of Life (OHRQoL) has been widely recognized as a valid parameter of assessment in almost every area of a person's physical and mental 
health care, including oral health., ${ }^{3,45}$ Periodontitis has been also associated with several systemic conditions, including adverse pregnancy outcomes, ${ }^{6}$ cardiovascular diseases, ${ }^{7}$ respiratory diseases, cancer, lupus, rheumatoid arthroses, diabetes mellitus $(\mathrm{DM})^{8}$ and chronic kidney disease. ${ }^{9}$ The biological plausibility of these associations relies mainly on the low systemic inflammatory burden that has been associated with periodontitis. ${ }^{10}$

Periodontal treatment can improve not only periodontal parameters such as gingival bleeding, probing pocket depth and attachment levels, but also subjective OHRQoL. Therefore, OHRQoL might be considered an important endpoint to fully assess the efficacy of periodontal therapy for oral health. Periodontal treatment has been shown to reduce shortterm levels of systemic markers of inflammation, ${ }^{10}$ surrogate outcomes, and may, therefore, contribute to the control of other diseases.

The aim of this paper was to review the results of different periodontal treatments and their impacts on patients' OHRQoL and systemic health. This paper was part of the Latin American Oral Health Association (LAOHA) Workshop that included experts from different Latin America countries. Contributions from the discussions are included in the article.

\section{Periodontal disease and Oral Health-Related Quality of Life (OHRQoL)}

In spite of its ubiquitous nature and the deleterious impact on the periodontium, periodontitis can progress as a 'silent disease' as it may be accompanied by swelling, bleeding and/or tooth mobility in the complete absence of pain. The recognition that health and well-being are not merely medical concepts, but are encompassed by the biopsychosocial model has been accepted for many years. OHRQoL has been defined as "an individual's perception of their position in life in the context of culture and value systems in which they live and in relation to their goals, expectations, standards and concerns". ${ }^{3}$ Periodontal diseases play a significant role in oral health and impact on the QoL of affected individuals ${ }^{4,5}$ and they may present a dose-response relationship. ${ }^{11}$ A systematic review demonstrated that gingivitis and periodontitis were associated with a negative impact on OHRQoL, with a significant impact on aspects related to function and esthetics, ${ }^{12}$ while another systematic review showed that tooth loss was associated with negative impacts on general OHRQoL. ${ }^{13}$ Periodontitis in young subjects and adults may be associated not only with worse OHRQoL, but also with higher dental anxiety. ${ }^{14,15}$ Therefore, the early diagnosis and treatment of periodontitis is important for the individual general health, and the perception of periodontitis as a "silent disease" should be changed. ${ }^{11}$

\section{Periodontal diseases and their association with systemic conditions}

Periodontitis has been associated with several systemic conditions, including adverse pregnancy outcomes $^{6}$, cardiovascular diseases, ${ }^{7,16}$ type $2 \mathrm{DM},{ }^{8}$ respiratory diseases, ${ }^{17}$ pneumonia mortality in hemodialysis patients, ${ }_{1}^{18}$ chronic kidney disease ${ }^{9}$ and metabolic syndrome. ${ }^{19}$ Early stages of atherosclerosis may be associated with severe chronic periodontitis related to endothelial and microvascular dysfunctions. ${ }^{20}$ The biological plausibility of these associations relies mainly on the low systemic inflammatory burden that has been associated with periodontitis. ${ }^{21}$ Increased levels of IL-1, IL- 6 and TNF- $\alpha$ were observed in blood samples of patients with periodontitis. ${ }^{21}$ A systematic review indicated that C-Reactive Protein levels were significantly higher among patients with chronic periodontitis. ${ }^{10}$ In Brazilian populations, this observation was confirmed in systemically healthy patients ${ }^{22}$ and patients with refractory arterial hypertension, ${ }^{23}$ type $2 \mathrm{DM}^{24}$ and chronic kidney disease. ${ }^{25}$ In diabetic patients, cardiovascular complications were associated with periodontitis, including increased overall mortality, coronary heart disease and stroke. ${ }^{8}$ A multi-center study in Brazil indicated that diabetic patients with periodontitis had increased odds of microvascular complications and of hospitalizations related to hyperglycemia and ketoacidosis. ${ }^{26}$

\section{Periodontal treatment}

Non-surgical (NSPT) and surgical periodontal treatment (SPT) are predictable procedures in terms 
of controlling infection, reducing probing pocket depth (PPD) and gaining clinical attachment level (CAL). ${ }^{27}$ Good plaque control is crucial to maintain periodontal health, and data related to tooth brushing behavior supported this statement. ${ }^{28,29,30}$ An 11-year study showed that tooth brushing was associated with a decrease in the number of teeth with periodontal pocketing. There was a clear dose-response relationship between tooth brushing frequency and change in the number of teeth with PPD $\geq 4 \mathrm{~mm} \cdot{ }^{30}$ Daily interdental brushing or flossing appeared to be the most effective procedures for reducing plaque and gingivitis scores, and was also the least expensive preventive therapy. ${ }^{31}$

Scaling and root planning (SRP) is considered the gold standard non-surgical treatment for periodontitis and its clinical efficacy has been well documented by several systematic reviews. ${ }^{32,33}$ Even teeth with extensive periodontal destruction may be retained and treated. Plaque removal and SRP may reduce gingival bleeding on probing in approximately $45 \%$ of sites. ${ }^{34}$ After NSPT, PPD reductions varied from 1-1.3 mm for pockets with initial PPD of 5-6 $\mathrm{mm}$ to 2-2.2 $\mathrm{mm}$ for PPD > $7 \mathrm{~mm}$; CAL could improve by $0.5-2 \mathrm{~mm} .{ }^{32,33} \mathrm{NSPT}$ may be delivered by conventional staged or full-mouth approaches. No clear difference existed between the 2 types of treatment, and the selected option may be chosen according to the specific situation. ${ }^{35}$

Tooth type, the degree of periodontal destruction, local factors, medical background and patients' age may interfere with the effectiveness of SRP. Non-molar teeth demonstrated higher PPD reduction after SRP than molars. ${ }^{35}$ However, NSPT alone may not be sufficient to reestablish periodontal health in cases of patients with advanced periodontitis. ${ }^{36}$ Thus, other forms of therapies, such as lasers, antiseptics, systemic antibiotics, host-modulators and probiotics have been suggested as adjuncts to SRP in order to potentiate the effects of this treatment. ${ }^{35}$ Among other adjunctive therapies to SRP, amoxicillin and metronidazole have proven strong scientific evidence for their use in daily clinical practice. The clinical benefits of this treatment protocol have been supported by recent systematic reviews $\mathrm{s}^{37,38,39,40}$ and randomized clinical trials (RCTs) with 1 to 2 years of follow up. ${ }^{41,42,43,44}$ In addition, a recent systematic review ${ }^{45}$ concluded that adjunctive probiotics could result in additional CA gain in adults with periodontitis. Nonetheless, further high-quality RCTs including microbiological analyses are necessary before determining whether probiotics should be used for the treatment of periodontitis in daily clinical practice.

Intrabony and furcation defects may be treated by conservative, resective or regenerative surgeries. A meta-analysis of studies evaluating conservative surgery for the treatment of intrabony defects found a PPD reduction of $2.9 \mathrm{~mm}$ and CA gain of $1.7 \mathrm{~mm}$ at 12 months post-treatment. ${ }^{46}$ Regenerative surgeries were mainly used for deep intrabony defects. Guided tissue regeneration and enamel matrix derivatives showed similar magnitudes of PPD reduction and CA gain: $1.2 \mathrm{~mm} \cdot{ }^{47} \mathrm{In}$ addition, the presence of furcation defects may increase the risk of tooth loss. Nibali et al. ${ }^{48}$ in a systematic review, described that the average tooth loss/year was 0.01 and 0.02 for molars without and with furcation involvement, respectively, in patients under supportive periodontal therapy for up to $10-15$ years. The results showed that around $10 \%$ of the molars treated by root resection or by regenerative procedures in furcation and intrabony defects were lost during supportive treatment. ${ }^{48}$

\section{Periodontal treatment and OHRQOL}

In addition to improvements in traditional clinical parameters, subjective OHRQoL should be considered an important endpoint for treatment with the aim of fully assessing the efficacy of periodontal therapy. Two systematic reviews were published on this topic. ${ }^{11,49}$ The focused question of these reviews was “Does surgical or non-surgical periodontal therapy improve the OHRQoL in adults with periodontal disease"? The results indicated a statistically significant improvement in OHRQoL after NSPT. No significant differences were reported between different forms of NSPT. SPT had a relatively lower impact on OHRQoL and a correlation between poor clinical response to therapy and poor OHRQoL outcomes was observed. Functional (eating/chewing), psychological (appearance/discomfort) and physical 
(pain) domains were the most affected at baseline, while functional and psychological domains as well as pain were those that improved the most after NSPT. OHRQoL improved with periodontal therapy, particularly after supragingival treatment, suggesting that this intervention was important for reducing the negative impacts of periodontal diseases in OHRQoL.

\section{Periodontal treatment and other diseases}

\section{Treatment of periodontitis and cardiovascular disease (CVD)}

Periodontal treatment has been shown to be effective in reducing short-term levels of systemic markers of inflammation. ${ }^{10}$ Short-term studies have shown a reduction in systemic markers associated with CVD, including IL-1, IL-6 and fibrinogen, ${ }^{23,25,50}$ after NSPT. A RCT indicated that the median values of $C$-reactive protein, total cholesterol and triglycerides were reduced after 6 months of periodontal treatment. ${ }^{22}$ Two pilot studies described outcomes in the management of patients with CVD, after 6 months of NSPT. ${ }^{23,25}$ Vidal et al..$^{23}$ observed reduction of cardiovascular markers, such as systolic and diastolic blood pressure and left ventricular mass in patients with severe chronic periodontitis and refractory arterial hypertension. These improvements were comparable with the introduction of a new medicine. In addition, six months after NSPT in patients with chronic renal diseases and periodontitis, there was a significant improvement in the estimated glomerular rate. ${ }^{25}$ The probable link between these observations was related to an improvement of the endothelial dysfunction. ${ }^{23,25}$

\section{Treatment of periodontitis and glycemic control}

Periodontitis may impair glycemic control in patients with $\mathrm{DM}{ }^{51}$ and periodontal treatment may improve glycemic control in patients with $\mathrm{DM}$, as demonstrated by systematic reviews with meta-analysis ${ }^{8,52}$ and RCTs. ${ }^{24,53}$ Reduction in HbA1c is an established outcome measure of successful DM treatment. ${ }^{54}$ Evidence derived from a recent meta-analyses showed that NSPT resulted in a statistically significant reduction in $\mathrm{HbA1C}$ levels at 3 months post-treatment of about $0.40 \%$ (range:
$0.27 \%-0.65 \%$, while at 6 months, the estimated reduction was lower. ${ }^{55}$ This decrease was considered equivalent to the introduction of a new medicine. A recent 1-year, double-blind and placebo-controlled $\mathrm{RCT}^{24}$ demonstrated a significant improvement of the mean C-reactive protein and mean glucose and HbA1C levels after NSPT in adults with periodontitis and type $2 \mathrm{DM}$. Merchant et al..$^{56}$ demonstrated that after 1.7 years of follow-up, long term periodontal care improved long-term glycemic control among individuals with type $2 \mathrm{DM}$ and periodontal disease. The reduction in HbA1c levels was greater among individuals with higher baseline HbA1c levels. Another group of investigators suggested that the beneficial effect of treating periodontitis on $\mathrm{HbA1c}$ may be sufficient to justify periodontal treatment in patients with type $2 \mathrm{DM}$ at accepted cost-effectiveness thresholds in the $\mathrm{UK}^{57}$. On the other hand, at least one recent $\mathrm{RCT}^{58}$ and one systematic review ${ }^{59}$ have suggested that not even the adjunctive use of systemic antibiotics during periodontal treatment was able to promote a significant reduction of $\mathrm{HbA1c}$ levels in patients with type $2 \mathrm{DM}$.

In summary, although the reduction of HbA1C levels after periodontal treatment has not yet been completely determined, therefore, considering the high prevalence of periodontal disease in type $2 \mathrm{DM}$ patients, the available data showing a positive effect of periodontal treatment on glycemic control and the oral health benefits for the patients' systemic health justify the inclusion of periodontal assessment and treatment in clinical guidelines for the management of DM. ${ }^{57}$

\section{Strategies for preventing periodontitis}

Most patients with periodontitis can be predictably treated and maintained. However, approximately $20-25 \%$ of patients with periodontitis will continue to exhibit disease progression, despite proper therapy and maintenance. The predictable periodontal treatment outcomes for most patients has changed the marketplace, in which patients are treated by general dentists and dental hygienists. Periodontics should include the management of and decision-making about tooth retention in advanced periodontitis cases, complex dental implant cases and control of systemic inflammation resulting from certain types of periodontitis. ${ }^{60}$ 
Population-based measures for preventing periodontal disease, primarily target changes in individual behavior. Interventions to prevent and control periodontal diseases are focused on the individual level, and therefore, address behavior rather than social conditions. However, adults are more difficult to reach when compared with children, if they do not seek the dentist of their own accord. The only prevention activity for periodontitis successfully performed at a population level seems to have been anti-smoking campaigns, although evidence of their efficacy is completely lacking. A major goal for the prevention of periodontal diseases should, therefore, be to change people's behavior in the direction of a lifestyle that is more conducive to health at an individual level ${ }^{61}$.

\section{Actions for prevention of periodontitis}

a. Anti-smoking campaigns and promotion of smoking cessation.

b. Promotion of oral hygiene practices. Among disadvantaged populations, a key factor of self-care hygiene practices is the ability to afford a toothbrush/toothpaste/interdental device. The production and sale of affordable toothbrushes would enable poorer populations to access and use these products. Partnerships between governments, national and multi-national companies, health professionals and local communities are necessary. Reduction of taxation levels on oral hygiene products would have a major effect by making these items affordable and accessible, particularly in populations from low- and middle- income countries in Latin America.

c. Stimulate the use of tele-dentistry, a broad variety of technologies and tactics to deliver virtual medical, health, and educational services to communities and dentists. The use of telehealth systems and methodologies in dentistry may include patient care and delivery of education using Information and Communication Technologies (ICTs). ${ }^{2}$ d. Dental schools may stimulate the concept of a health promotion environment for students, staff and the community.

Gingivitis, mild forms of periodontitis and edentulism appear to be declining. ${ }^{62}$ However, the percentage of severe periodontitis remained unchanged. ${ }^{63}$ This trend may be an indication that primary prevention, including improvement of oral hygiene procedures and regular programs of professional health care have contributed to the reduction in the prevalence of gingivitis and mild forms of periodontitis. On the other hand, because of the global population growth (from 5.5 billion in 1990 to 7.4 billion in 2015), ageing societies (globally, the proportion of people 65 years and older increased from $6.0 \%$ in 1990 to $8.2 \%$ in 2015) and increased tooth retention, the number of people affected by periodontitis has grown substantially, increasing the total burden of this disease globally. Estimates have indicated that between 1990 and 2013, the number of people affected by severe periodontitis increased by $67 \%{ }^{64}$ The global economic impact of oral disease in 2010 has been estimated at US $\$ 442$ billion. ${ }^{65}$

By 2050, it is estimated that $22 \%$ of the world's population will be older than 60 years of age. As a result, $80 \%$ of older adults will suffer from at least one chronic disease, and 50\% will suffer from at least 2 disorders. ${ }^{66}$ With the world population aging, early identification of individuals with a particular aging trajectory is necessary, as these are individuals at risk for early development of non-communicable chronic diseases (NCD), such as DM and CVD. By the year of 2030, the estimated percentage of worldwide deaths caused by NCD will be 70\%. This trend would be seen for high, middle and low-income countries. ${ }^{67}$ Care of NCD patients in the dental office is both a challenge and an opportunity. Periodontal professionals must increase their level of communication with other healthcare professionals, especially physicians and nurses, to identify all possible relations between these chronic diseases. Periodontitis should be regarded as a "sign post" condition, which could indicate that a patient may have an underlying chronic NCD (e.g. undiagnosed DM). The number of teeth maintained is a marker for general health, healthy aging and a longer lifespan. Sharing the importance 
and significance of retained teeth with both dental and non-dental health-care providers may provide a valuable impetus to improve oral hygiene and retain teeth. Periodontal disease, tooth loss and longevity may be related. ${ }^{68}$

\section{Challenges facing the field of periodontology in the 21 st Century: concluding remarks}

a. Promote adequate communication between general dentists and periodontists, so that they know in which periodontal affections the patient could require a more specialized treatment, especially in those cases when non-surgical therapy does not achieve periodontal health.

b. Increase participation of periodontists in the decision-making about tooth extraction and implant reconstruction, and management of advanced, complex periodontal cases. Dentists ARE trained to PRESERVE teeth. ${ }^{69}$

c. Periodontists should establish connections with non-dental healthcare professionals, including physicians and nurses, who urgently need to know about the fundamentals of the onset and progression of periodontal diseases.

d. Dental schools could participate in developing educational programs for dentists and for nondental healthcare professionals.

e. National Dental Associations could help policy makers and governments to promote the recognition of oral health as a vital and integral aspect of general health and wellbeing.

\section{Acknowledgments}

This paper was prepared for the consensus meeting titled "Periodontal disease and its impact on general health in Latin America - Latin American Consensus", promoted by the Latin American Oral Health Association (LAOHA) and Colgate Palmolive Co. with participation of experts from the region, including representatives from Periodontal Societies of Latin America. All participants had the opportunity to review the content and, eventually make their own contributions. Consensus was based on this paper. The authors point out that they have no conflicts of interest.

\section{References}

1. Papapanou PN, Sanz M, Buduneli N, Dietrich T, Feres M, Fine DH, et al. Periodontitis: Consensus report of workgroup 2 of the 2017 World Workshop on the Classification of Periodontal and Peri-Implant Diseases and Conditions. J Periodontol. 2018 Jun;89 Suppl 1:S173-82. https://doi.org/10.1002/JPER.17-0721

2. American Dental Association - ADA. D9995 and D9996 ADA guide: version 1. Chicago: American Dental Association, 2017 [cited 2018 Dec 20]. Available from: https://www.ada.org/ /media/ADA/Publications/Files/D9995andD9996_ ADAGuidetoUnderstandingandDocumentingTeledentistryEvents_v1_2017Jul17.pdf? la=en

3. Sischo L, Broder HL. Oral health-related quality of life: what, why, how, and future implications. J Dent Res. 2011 Nov;90(11):1264-70. https://doi.org/10.1177/0022034511399918

4. Meusel DR, Ramacciato JC, Motta RH, Brito Júnior RB, Flório FM. Impact of the severity of chronic periodontal disease on quality of life. J Oral Sci. 2015 Jun;57(2):87-94. https://doi.org/10.2334/josnusd.57.87

5. Needleman I, McGrath C, Floyd P, Biddle A. Impact of oral health on the life quality of periodontal patients. J Clin Periodontol. 2004 Jun;31(6):454-7. https://doi.org/10.1111/j.1600-051X.2004.00498.x

6. Ide M, Papapanou PN. Epidemiology of association between maternal periodontal disease and adverse pregnancy outcomes-systematic review. J Clin Periodontol. 2013 Apr;40 Suppl 14:S181-94. https://doi.org/10.1111/icpe.12063

7. Humphrey LL, Fu R, Buckley DI, Freeman M, Helfand M. Periodontal disease and coronary heart disease incidence: a systematic review and meta-analysis. J Gen Intern Med. 2008 Dec;23(12):2079-86. https://doi.org/10.1007/s11606-008-0787-6

8. Graziani F, Gennai S, Solini A, Petrini M. A systematic review and meta-analysis of epidemiologic observational evidence on the effect of periodontitis on diabetes An update of the EFP-AAP review. J Clin Periodontol. 2018 Feb;45(2):167-87. https://doi.org/10.1111/jcpe.12837

9. Chambrone L, Foz AM, Guglielmetti MR, Pannuti CM, Artese HP, Feres M, et al. Periodontitis and chronic kidney disease: a systematic review of the association of diseases and the effect of periodontal treatment on estimated glomerular filtration rate. J Clin Periodontol. 2013 May;40(5):443-56. https://doi.org/10.1111/icpe.12067 
Fischer RG, Lira Junior R, Retamal-Valdes B, Figueiredo LC, Malheiros A, Stewart B, et al.

10. Paraskevas S, Huizinga JD, Loos BG. A systematic review and meta-analyses on C-reactive protein in relation to periodontitis. J Clin Periodontol. 2008 Apr;35(4):277-90. https://doi.org/10.1111/j.1600-051X.2007.01173.x

11. Buset SL, Walter C, Friedmann A, Weiger R, Borgnakke WS, Zitzmann NU. Are periodontal diseases really silent? A systematic review of their effect on quality of life. J Clin Periodontol. 2016 Apr;43(4):333-44. https://doi.org/10.1111/icpe.12517

12. Ferreira MC, Dias-Pereira AC, Branco-de-Almeida LS, Martins CC, Paiva SM. Impact of periodontal disease on quality of life: a systematic review. J Periodontal Res. 2017 Aug;52(4):651-65. https://doi.org/10.1111/jre.12436

13. Haag DG, Peres KG, Balasubramanian M, Brennan DS. Oral Conditions and Health-Related Quality of Life: A Systematic Review. J Dent Res. 2017 Jul;96(8):864-74. https://doi.org/10.1177/0022034517709737

14. Levin L, Zini A, Levine J, Weiss M, Lev R, Chebath Taub D, et al. Demographic profile, Oral Health Impact Profile and Dental Anxiety Scale in patients with chronic periodontitis: a case-control study. Int Dent J. 2018 Aug;68(4):269-78. https://doi.org/10.1111/idj.12381

15. Levin L, Zini A, Levine J, Weiss M, Lev RA, Hai A, et al. Dental anxiety and oral health-related quality of life in aggressive periodontitis patients. Clin Oral Investig. 2018 Apr;22(3):1411-22. https://doi.org/10.1007/s00784-017-2234-8

16. Tonetti MS, Van Dyke TE; Working group 1 of the joint EFP/AAP workshop. Periodontitis and atherosclerotic cardiovascular disease: consensus report of the Joint EFP/AAP Workshop on Periodontitis and Systemic Diseases. J Clin Periodontol. 2013 Apr;40 Suppl 14:S24-9. https://doi.org/10.1111/icpe.12089

17. Sabharwal A, Gomes-Filho IS, Stellrecht E, Scannapieco FA. Role of periodontal therapy in management of common complex systemic diseases and conditions: an update. Periodontol 2000. 2018 Oct;78(1):212-26. https://doi.org/10.1111/prd.12226

18. Iwasaki M, Taylor GW, Awano S, Yoshida A, Kataoka S, Ansai T, et al. Periodontal disease and pneumonia mortality in haemodialysis patients: a 7-year cohort study. J Clin Periodontol. 2018 Jan;45(1):38-45. https://doi.org/10.1111/icpe.12828

19. Nibali L, D'Aiuto F, Griffiths G, Patel K, Suvan J, Tonetti MS. Severe periodontitis is associated with systemic inflammation and a dysmetabolic status: a case-control study. J Clin Periodontol. 2007 Nov;34(11):931-7. https://doi.org/10.1111/j.1600-051X.2007.01133.x

20. Lira-Junior R, Figueredo CM, Bouskela E, Fischer RG. Severe chronic periodontitis is associated with endothelial and microvascular dysfunctions: a pilot study. J Periodontol. 2014 Dec;85(12):1648-57. https://doi.org/10.1902/jop.2014.140189

21. Loos BG. Systemic markers of inflammation in periodontitis. J Periodontol. 2005;76(11 Suppl):2106-15. https://doi.org/10.1902/jop.2005.76.11-S.2106

22. Caúla AL, Lira-Junior R, Tinoco EM, Fischer RG. The effect of periodontal therapy on cardiovascular risk markers: a 6-month randomized clinical trial. J Clin Periodontol. 2014 Sep;41(9):875-82. https://doi.org/10.1111/icpe.12290

23. Vidal F, Figueredo CM, Cordovil I, Fischer RG. Periodontal therapy reduces plasma levels of interleukin-6, C-reactive protein, and fibrinogen in patients with severe periodontitis and refractory arterial hypertension. J Periodontol. 2009 May;80(5):786-91. https://doi.org/10.1902/jop.2009.080471

24. Mourão Carillo Jr R. LSMCAFRG. Homeopathy and periodontal treatment in type II diabetic patients: a 1-year randomized clinical trial. Braz Dent J. 2019 Mar-Apr;30(2):139-45. https://doi.org/10.1590/0103-6440201902124

25. Almeida S, Figueredo CM, Lemos C, Bregman R, Fischer RG. Periodontal treatment in patients with chronic kidney disease: a pilot study. J Periodontal Res. 2017 Apr;52(2):262-7. https://doi.org/10.1111/jre.12390

26. Oliveira LS, Lira-Junior R, Figueredo CM, Gomes MB, Fischer RG. Self-Reported Periodontitis and Complications in Type 1 Diabetes Patients: A Brazilian Nationwide Survey. Braz Dent J. 2016 Sep-Oct;27(5):599-603. https://doi.org/10.1590/0103-6440201601054

27. Feres M, Faveri M, Figueiredo LC, Teles R, Flemmig T, Williams R, et al. Group B Initiator paper. Non-surgical periodontal therapy: mechanical debridement, antimicrobial agents and other modalities. J Int Acad Periodontol. 2015 Jan;17(1 Suppl):21-30.

28. Kalf-Scholte SM, Van der Weijden GA, Bakker E, Slot DE. Plaque removal with triple-headed vs single-headed manual toothbrushes-a systematic review. Int J Dent Hyg. 2018 Feb;16(1):13-23. https://doi.org/10.1111/idh.12283

29. Van der Sluijs E, Slot DE, Hennequin-Hoenderdos NL, Van der Weijden GA. A specific brushing sequence and plaque removal efficacy: a randomized split-mouth design. Int J Dent Hyg. 2018 Feb;16(1):85-91. https://doi.org/10.1111/idh.12262

30. Joshi S, Suominen AL, Knuuttila M, Bernabé E. Toothbrushing behaviour and periodontal pocketing: An 11-year longitudinal study. J Clin Periodontol. 2018 Feb;45(2):196-203. https://doi.org/10.1111/jcpe.12844

31. Hyde S, Dupuis V, Mariri BP, Dartevelle S. Prevention of tooth loss and dental pain for reducing the global burden of oral diseases. Int Dent J. 2017 Sep;67 Suppl 2:19-25. https://doi.org/10.1111/idj.12328

32. Van der Weijden GA, Timmerman MF. A systematic review on the clinical efficacy of subgingival debridement in the treatment of chronic periodontitis. J Clin Periodontol. 2002;29(s3 Suppl 3):55-71. https://doi.org/10.1034/i.1600-051X.29.s3.3.x

33. Smiley CJ, Tracy SL, Abt E, Michalowicz BS, John MT, Gunsolley J, et al. Systematic review and meta-analysis on the nonsurgical treatment of chronic periodontitis by means of scaling and root planing with or without adjuncts. J Am Dent Assoc. 2015 Jul;146(7):508-24.e5. https://doi.org/10.1016/i.adaj.2015.01.028

34. Cobb CM. Clinical significance of non-surgical periodontal therapy: an evidence-based perspective of scaling and root planing. J Clin Periodontol. 2002 May;29(s2 Suppl 2):6-16. https://doi.org/10.1034/i.1600-051X.29.s2.4.x 
- Periodontal disease and its impact on general health in Latin America. Section V: Treatment of periodontitis

35. Graziani F, Karapetsa D, Alonso B, Herrera D. Nonsurgical and surgical treatment of periodontitis: how many options for one disease? Periodontol 2000. 2017 Oct;75(1):152-88. https://doi.org/10.1111/prd.12201

36. Feres M, Figueiredo LC, Soares GM, Faveri M. Systemic antibiotics in the treatment of periodontitis. Periodontol 2000. 2015 Feb;67(1):131-86. https://doi.org/10.1111/prd.12075

37. Sgolastra F, Gatto R, Petrucci A, Monaco A. Effectiveness of systemic amoxicillin/metronidazole as adjunctive therapy to scaling and root planing in the treatment of chronic periodontitis: a systematic review and meta-analysis. J Periodontol. 2012 Oct;83(10):1257-69. https://doi.org/10.1902/jop.2012.110625

38. Keestra JA, Grosjean I, Coucke W, Quirynen M, Teughels W. Non-surgical periodontal therapy with systemic antibiotics in patients with untreated aggressive periodontitis: a systematic review and meta-analysis. J Periodontal Res. 2015 Dec;50(6):689-706. https://doi.org/10.1111/jre.12252

39. Keestra JA, Grosjean I, Coucke W, Quirynen M, Teughels W. Non-surgical periodontal therapy with systemic antibiotics in patients with untreated chronic periodontitis: a systematic review and meta-analysis. J Periodontal Res. 2015 Jun;50(3):294-314. https://doi.org/10.1111/ire.12221

40. Zandbergen D, Slot DE, Niederman R, Van der Weijden FA. The concomitant administration of systemic amoxicillin and metronidazole compared to scaling and root planing alone in treating periodontitis: =a systematic review=. BMC Oral Health. 2016 Feb;16(1):27. https://doi.org/10.1186/s12903-015-0123-6

41. Goodson JM, Haffajee AD, Socransky SS, Kent R, Teles R, Hasturk H, et al. Control of periodontal infections: a randomized controlled trial I. The primary outcome attachment gain and pocket depth reduction at treated sites. J Clin Periodontol. 2012 Jun;39(6):526-36. https://doi.org/10.1111/j.1600-051X.2012.01870.x

42. Harks I, Koch R, Eickholz P, Hoffmann T, Kim TS, Kocher T, et al. Is progression of periodontitis relevantly influenced by systemic antibiotics? A clinical randomized trial. J Clin Periodontol. 2015 Sep;42(9):832-42. https://doi.org/10.1111/icpe.12441

43. Tamashiro NS, Duarte PM, Miranda TS, Maciel SS, Figueiredo LC, Faveri M, et al. Amoxicillin Plus Metronidazole Therapy for Patients with Periodontitis and Type 2 Diabetes: a 2-year Randomized Controlled Trial. J Dent Res. 2016 Jul;95(7):829-36. https://doi.org/10.1177/0022034516639274

44. Borges I, Faveri M, Figueiredo LC, Duarte PM, Retamal-Valdes B, Montenegro SC, et al. Different antibiotic protocols in the treatment of severe chronic periodontitis: a 1-year randomized trial. J Clin Periodontol. 2017 Aug;44(8):822-32. https://doi.org/10.1111/icpe.12721

45. Ikram S, Hassan N, Raffat MA, Mirza S, Akram Z. Systematic review and meta-analysis of double-blind, placebo-controlled, randomized clinical trials using probiotics in chronic periodontitis. J Investig Clin Dent. 2018 Aug;9(3):e12338. https://doi.org/10.1111/jicd.12338

46. Graziani F, Gennai S, Cei S, Cairo F, Baggiani A, Miccoli M, et al. Clinical performance of access flap surgery in the treatment of the intrabony defect. A systematic review and meta-analysis of randomized clinical trials. J Clin Periodontol. 2012 Feb;39(2):145-56. https://doi.org/10.1111/j.1600-051X.2011.01815.x

47. Needleman IG, Worthington HV, Giedrys-Leeper E, Tucker RJ. Guided tissue regeneration for periodontal infra-bony defects. Cochrane Database Syst Rev. 2006 Apr;(2):CD001724. https://doi.org/10.1002/14651858.CD001724.pub2

48. Nibali L, Zavattini A, Nagata K, Di lorio A, Lin GH, Needleman I, et al. Tooth loss in molars with and without furcation involvement - a systematic review and meta-analysis. J Clin Periodontol. 2016 Feb;43(2):156-66. https://doi.org/10.1111/icpe.12497

49. Shanbhag S, Dahiya M, Croucher R. The impact of periodontal therapy on oral health-related quality of life in adults: a systematic review. J Clin Periodontol. 2012 Aug;39(8):725-35. https://doi.org/10.1111/i.1600-051X.2012.01910.x

50. Vidal F, Cordovil I, Figueredo CM, Fischer RG. Non-surgical periodontal treatment reduces cardiovascular risk in refractory hypertensive patients: a pilot study. J Clin Periodontol. 2013 Jul;40(7):681-7. https://doi.org/10.1111/icpe.12110

51. Tsai C, Hayes C, Taylor GW. Glycemic control of type 2 diabetes and severe periodontal disease in the US adult population. Community Dent Oral Epidemiol. 2002 Jun;30(3):182-92. https://doi.org/10.1034/i.1600-0528.2002.300304.x

52. Teeuw WJ, Gerdes VE, Loos BG. Effect of periodontal treatment on glycemic control of diabetic patients: a systematic review and metaanalysis. Diabetes Care. 2010 Feb;33(2):421-7. https://doi.org/10.2337/dc09-1378

53. Quintero AJ, Chaparro A, Quirynen M, Ramirez V, Prieto D, Morales $H$, et al. Effect of two periodontal treatment modalities in patients with uncontrolled type 2 diabetes mellitus: A randomized clinical trial. J Clin Periodontol. 2018 Sep;45(9):1098-106. https://doi.org/10.1111/icpe.12991

54. Chapple IL, Genco R. Diabetes and periodontal diseases: consensus report of the Joint EFP/AAP Workshop on Periodontitis and Systemic Diseases. J Clin Periodontol. 2013 Apr;40 Suppl 14:S106-12. https://doi.org/10.1111/jicpe.12077

55. Madianos PN, Koromantzos PA. An update of the evidence on the potential impact of periodontal therapy on diabetes outcomes. J Clin Periodontol. 2018 Feb;45(2):188-95. https://doi.org/10.1111/icpe.12836

56. Merchant AT, Georgantopoulos P, Howe CJ, Virani SS, Morales DA, Haddock KS. Effect of Long-Term Periodontal Care on Hemoglobin Alc in Type 2 Diabetes. J Dent Res. 2016 Apr;95(4):408-15. https://doi.org/10.1177/0022034515622197

57. Solowiej-Wedderburn J, Ide M, Pennington M. Cost-effectiveness of non-surgical periodontal therapy for patients with type 2 diabetes in the UK. J Clin Periodontol. 2017 Jul;44(7):700-7. https://doi.org/10.1111/icpe.12746

58. Miranda TS, Feres M, Perez-Chaparro PJ, Faveri M, Figueiredo LC, Tamashiro NS, et al. Metronidazole and amoxicillin as adjuncts to scaling and root planing for the treatment of type 2 diabetic subjects with periodontitis: 1 -year outcomes of a randomized placebo-controlled clinical trial. J Clin Periodontol. 2014 Sep;41(9):890-9. https://doi.org/10.1111/jcpe.12282 
59. Lira Junior R, Santos CM, Oliveira BH, Fischer RG, Santos AP. Effects on HbAlc in diabetic patients of adjunctive use of systemic antibiotics in nonsurgical periodontal treatment: A systematic review. J Dent. 2017 Nov;66:1-7. https://doi.org/10.1016/i.jdent.2017.08.001

60. Kornman KS, Giannobile WV, Duff GW. Quo vadis: what is the future of periodontics? How will we get there? Periodontol 2000. 2017 Oct;75(1):353-71. https://doi.org/10.1111/prd.12217

61. Sälzer S, Alkilzy M, Slot DE, Dörfer CE, Schmoeckel J, Splieth CH; Chairs of Working Group 3; ORCA. Socio-behavioural aspects in the prevention and control of dental caries and periodontal diseases at an individual and population level [Internet]. J Clin Periodontol. 2017 Mar;44 Suppl 18:S106-15. https://doi.org/10.1111/icpe.12673

62. Kassebaum NJ, Bernabé E, Dahiya M, Bhandari B, Murray CJ, Marcenes W. Global Burden of Severe Tooth Loss: A Systematic Review and Meta-analysis. J Dent Res. 2014 Jul;93(7 Suppl):20S-8S. https://doi.org/10.1177/0022034514537828

63. Hugoson A, Norderyd O. Has the prevalence of periodontitis changed during the last 30 years? J Clin Periodontol. 2008 Sep;35(8 Suppl):338-45. https://doi.org/10.1111/i.1600-051X.2008.01279.x

64. GBD 2015 Disease and Injury Incidence and Prevalence Collaborators. Global, regional, and national incidence, prevalence, and years lived with disability for 310 diseases and injuries, 1990-2015: a systematic analysis for the Global Burden of Disease Study 20. Lancet. 2016;388(10053):1545-602. https://doi.org/10.1016/S0140-6736(16)31678-6

65. Listl S, Galloway J, Mossey PA, Marcenes W. Global economic impact of dental diseases. J Dent Res. 2015 Oct;94(10):1355-61. https://doi.org/10.1177/0022034515602879

66. Kanasi E, Ayilavarapu S, Jones J. The aging population: demographics and the biology of aging. Periodontol 2000. 2016 Oct;72(1):13-8. https://doi.org/10.1111/prd.12126

67. Lamster IB. Geriatric periodontology: how the need to care for the aging population can influence the future of the dental profession. Periodontol 2000. 2016 Oct;72(1):7-12. https://doi.org/10.1111/prd.12157

68. Friedman PK, Lamster IB. Tooth loss as a predictor of shortened longevity: exploring the hypothesis. Periodontol 2000. 2016 Oct;72(1):142-52. https://doi.org/10.1111/prd.12128

69. Giannobile WV, Lang NP. Are dental implants a panacea or should we better strive to save teeth? J Dent Res. 2016 Jan;95(1):5-6. https://doi.org/10.1177/0022034515618942 